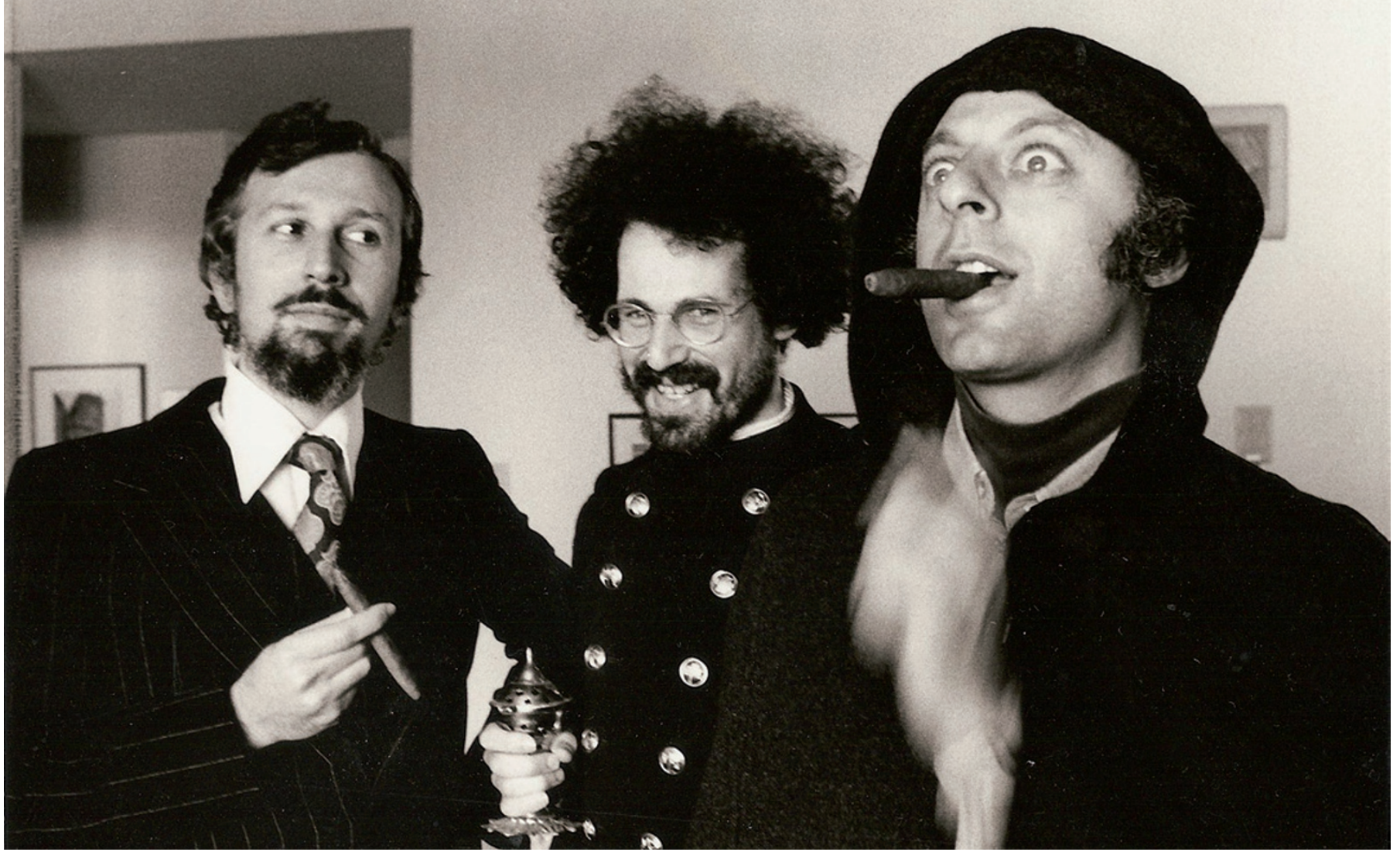

In the 1970s, Jack Sarfatti, Saul-Paul Sirag, Fred Alan Wolf and others in the Fundamental Fysiks Group opened up discussions of quantum mechanics.

PHYSICS

\section{Quantum outsiders}

\section{Hugh Gusterson enjoys a history of the quirky group that pursued quantum physics when it was unfashionable.}

\section{I} $\mathrm{t}$ is hard to write a book about quantum mechanics that is at once intellectually serious and a page-turner. But David Kaiser succeeds in his account of a neglected but important group of physicists who brought together quantum mechanics, Eastern religion, parapsychology and the hallucinogen LSD.

Kaiser, a historian of science at the Massachusetts Institute of Technology in Cambridge, seeks to understand why a set of mind-bending ideas developed in the 1920s and 1930s by European physicists - including Werner Heisenberg, Niels Bohr, Max Born and Wolfgang Pauli - were largely barred from discussion in mainstream US physics after the Second World War. At the heart of quantum mechanics lie these challenging ideas: that electrons behave like waves and particles; that one can know a particle's precise location or momentum but not both; that the act of observing a particle changes its behaviour; and that particles seem to communicate with one another across great distances - the phenomena of nonlocality and entanglement that Albert Einstein derided as "spooky action at a distance".

These radical concepts led to the field of quantum information science and the emergence of ultrasecure technologies, based on quantum encryption, for transferring money or electronic votes. Such concepts were also, in ways that Kaiser does not explore, influential beyond physics. Their critique of reductionism and emphasis on the effects of observers led to the rise of 'poststructuralist' thinking in the humanities. But during the cold war, the profound

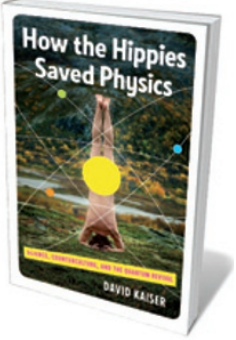

How the Hippies Saved Physics:

Science,

Counterculture, and the Quantum Revival

DAVID KAISER W. W. Norton: 2011. 372 pp. $\$ 26.95$, $£ 19.99$ philosophical issues raised by quantum mechanics were seen by many in physics as an unnecessary distraction.

Tracing shifts in university lecture notes and textbooks after the Second World War, Kaiser argues that the fundamental strangeness of quantum reality was drained out of academic physics by the "high-throughput pedagogy" that accompanied a sixfold increase in $\mathrm{PhD}$ student numbers. Pressure to produce gadgets to change the course of the cold war left little time for philosophizing.

This meant that some of the key work in quantum mechanics in the 1970s and 1980s was done by a motley crew of young physicists, who worked largely outside universities and published in obscure journals such as Epistemological Letters - "a hand-typed, mimeographed newsletter". They included Elizabeth Rauscher, Jack Sarfatti, Fred Alan Wolf, Saul-Paul Sirag, John Clauser and Fritjof Capra. The centre of their intellectual universe was the San Francisco Bay area. Many were associated with the Fundamental Fysiks Group, an open discussion group about quantum mechanics that started meeting in 1975 at the Lawrence Berkeley Laboratory in California.

Unable to secure professorships in the shrunken job market of the time, some of the group lived on the edge of destitution. The luckiest was Fritjof Capra, whose book The Tao of Physics (Wildwood House, 1975) was translated into 23 languages and brought him financial security. Other Fysiks members cobbled together eccentric funding sources: George Weissmann founded a company selling a Tibetan herbal remedy until the US Food and Drug Administration banned his product. And others secured funding through the Pentagon to see whether quantum mechanics might explain the apparent spoon-bending abilities of psychics such as Uri Geller and to investigate telepathy.

Three New Age guruentrepreneurs were even more colourful. Werner Erhard, founder of the Est movement for $\rightarrow$ NATURE.COM

David Kaiser on university funding: go.nature.com/oflvik 
self-transformation, sponsored opulent conferences on quantum mechanics at his San Francisco mansion. Members of the Fundamental Fysiks Group and Nobel laureates both enjoyed Erhard's patronage despite some physicists' concerns about Est's practices. Michael Murphy, founder of the Esalen retreat on the California coast, sponsored workshops at which physicists alternated their hot-tub discussions of quantum mechanics with massages and, in some cases, LSD trips.

A third New Age activist and impresario, Ira Einhorn, somehow persuaded senior executives at Bell Telephone that the company should copy and mail the latest papers on quantum mechanics to some 300 people - an early postal version of an e-mail distribution list. This arrangement came to an abrupt end when the police discovered the decomposing body of Einhorn's girlfriend in a trunk in his apartment.

Interspersing entertaining anecdotes with explanations of concepts in quantum physics, Kaiser's book can be read on many levels. At its most challenging, it is an intellectual history of quantum mechanics. But it is also a yarn about an eccentric group of physicists who refused to be defeated by their marginalization within their own discipline. And, as social history, it offers a window onto one of the most colourful periods of twentiethcentury US history.

The book makes important observations about the social dynamics of physics in the United States during the cold war. Kaiser argues that, even as military patronage pumped massive financial resources into physics, the discipline's horizons shrank. University physicists disdained the philosophical questions that had enlivened pre-war European physics and developed a narrowly instrumentalist pedagogy that sometimes became a straitjacket.

Kaiser describes some students holding secret meetings to discuss quantum mechanics behind their advisers' backs, having been warned that "thinking seriously about foundations was a waste of time and a detriment to one's career". He also notes that the editor of Physical Review banned articles discussing interpretations of quantum mechanics; a brilliant experiment on Bell's theorem by John Clauser was scarcely cited because of the prevailing orthodoxy. Clauser was told that his experiment was not "real physics", and he had a terrible time on the job market. By contrast, the heroes of Kaiser's story "strove to expand the physics profession's collective mental space". This is an equally apt description of Kaiser's approach in this illuminating book.

Hugh Gusterson is professor of anthropology and sociology at George Mason University, Fairfax, Virginia 22030, USA. His latest book is People of the Bomb. e-mail:hgusters@gmu.edu

\section{EVOLUTION}

\section{The long trek to domesticated bliss}

\author{
Our fondness for fauna comes from an evolved \\ human need to nurture, argues Juliet Clutton-Brock.
}

I n The Animal Connection, palaeoanthropologist Pat Shipman describes how humans have been connected with animals for the past 2.6 million years, and how this relationship distinguishes us from other animals. She argues that the evolution of human behaviour was driven by this connection in three stages: toolmaking, language and domestication of animals and plants. But Shipman's book is more a review of what has long been known than the "New Perspective" promised by its subtitle.

Shipman starts by outlining the characteristics that separate the fossil hominin Ardipithecus ramidus - found in Ethiopia and dated to around 4.2 million years ago - from other primates. Continuing on through the australopithecines, she describes how, from 2.6 million years ago, "Hominids transformed rocks into stone tools and stone tools transformed hominids from bipedal apes that are [sic] basically herbivorous into predators". This was the beginning of the animal connection, accompanying the evolution of Homo erectus and its expansion out of Africa.

Shipman goes on to discuss the evolution of human language, the origin of symbolism and the theory of mind. She proposes that language followed from the need for humans to communicate animalrelated information in their quest for food. Language "allowed humans to talk about animals and in time, with animals", she says.

Towards the end of the Pleistocene, around 32,000 years ago, came the first domestic dogs. The cultivation of plants and the domestication of livestock in many parts of the world followed in the early Holocene. Shipman describes what is known about this process, including arguments around the outdated view that the primary motive for domestication was the provision of meat. She also explores 'selfdomestication' - the theory that, from

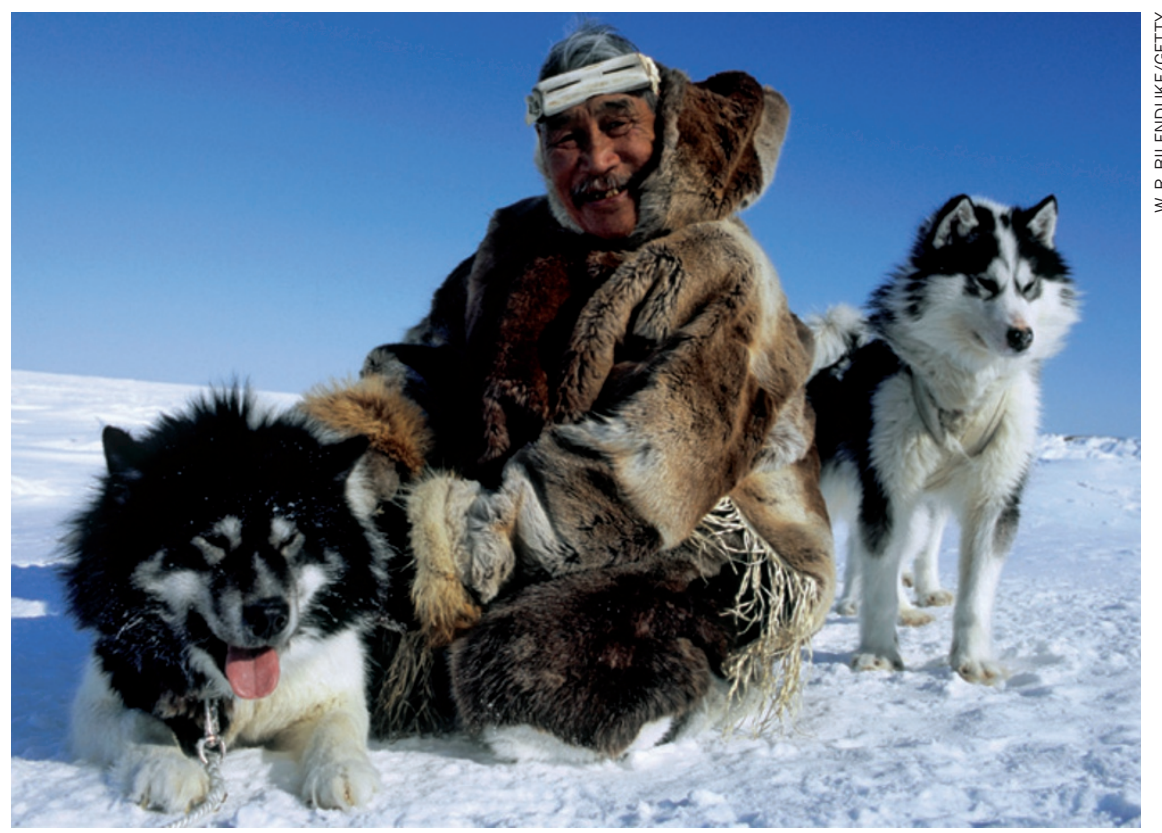

Domesticated 32,000 years ago, dogs remain central to many societies, including the Inuit. 
scavenging around human settlements, wild animals gradually became habituated, were selected for tameness, and over generations became domesticated. Shipman outlines the distinction of true domestication from taming as "the permanence of the change in the wild animal". Yet she misses what I believe is the essence of why humans relate so readily to animals, which is supported by Sarah Blaffer Hrdy in her book on the evolution of hominins as cooperative breeders, Mothers and Others (Harvard University Press, 2009).

Humans, Blaffer Hrdy says, alone among the great apes, readily nurture each other's children. Without this help, few children in hunter-gatherer societies would survive to adulthood. There are many examples of huntergatherers extending the shared care of their infants to the adoption of young animals. So the human desire to enfold other species within our societies may be explained as having evolved from the combined instincts for nurture and domination.

I believe that the inborn human desire to nurture children and animals was followed by the domestication of dogs, and all the livestock animals whose social behaviour allowed it, in hunter-gatherer societies that were under pressure in the early Holocene from population growth and climate change. Shipman describes the conventional theory that domestication follows from the selection by humans of favoured attributes. I see the process as more complicated and in two parts: biological and cultural.

It is now accepted that some wild animals have cultures, that is, the inheritance of learned behaviour. With taming, an animal is brought into a protected place where it learns a new set of social relationships, as well as new feeding and reproductive strategies. Biological domestication is complete only when this 'culture' becomes heritable.

Shipman ends with the conviction that the ancient, innate connection between humans and animals is grossly underestimated in today's urban landscape. I see little evidence for this. Despite the inexorable spread of megacities and factory farms, the connection with both domestic and wild animals still occupies the minds and lives of innumerable people around the world.

Juliet Clutton-Brock is a research associate at the Natural History Museum, London. Her forthcoming book is Animals as Domesticates: A World View Through History. e-mail:juliet.cb@btinternet.com

\section{ASTRONOMY}

\section{Supernova century}

\section{Jay Pasachoff relishes a novel that brings to life the scientific stars of the 1600s.}

$\mathrm{S}$ omewhat eclipsed in popular culture by his great Italian contemporary Galileo Galilei, Johannes Kepler is finally achieving the iconic status he has long held in science. In 2009, the seventeenth-century German astronomer was the subject of an opera by US composer Philip Glass (Nature 462, 724; 2009). Now, Stuart Clark's novel the first in a trilogy about famous astronomers - puts fictional flesh on the bones of Kepler's life and times to enjoyable effect.

Only 60 years or so after Copernicus provided the idea of the heliocentric Universe, Kepler worked out the orbits of the planets. The story told in The Sky's Dark Labyrinth, which takes its name from a phrase in Galileo's 1623 book Il Saggiatore (The Assayer), is well known. Kepler assisted aristocratic court astronomer Tycho Brahe in Prague, taking over Tycho's precise observations of Mars and its changing position in the sky. From these studies, Kepler deduced his three laws of planetary motion, the first two of which he published in Astronomia Nova (The New Astronomy) in 1609, the same year that Galileo first pointed his telescope skywards.

Clark depicts the clash of two strong personalities: the haughty Tycho, and Kepler, whose confidence in his own mathematical abilities never wavered. He draws, too,

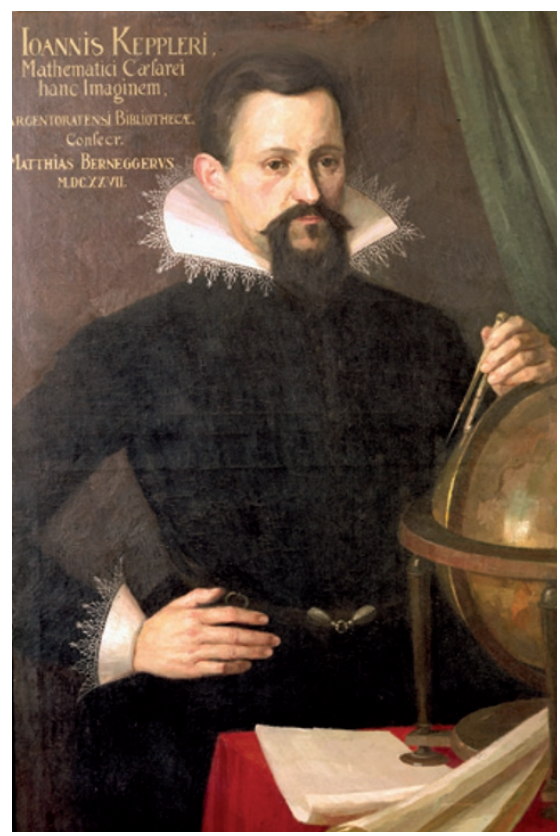

Astronomer Johannes Kepler in his final decade.

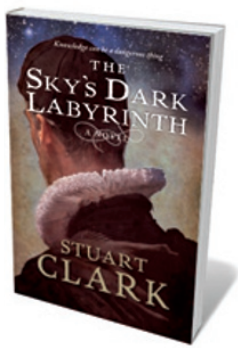

The Sky's Dark Labyrinth: A Novel STUART CLARK Polygon: 2011 272 pp. £12.99

Working with these 'planetary tables', Kepler accurately predicted that transits of Mercury and of Venus would occur in 1631. The first of these was observed in Europe, but he did not realize that there would soon be a second transit of Venus, in 1639. (The next transit of Venus will be visible from Earth on 5-6 June 2012, depending on the observer's location; the following one is not until 2117.)

The author paints the conflicts between Lutherans and Catholics that drove the Lutheran Kepler from Graz to Prague, and that helped govern how Pope Urban VIII treated Galileo. Clark describes the blood that literally flowed during the internecine warfare between Rudolph II and his brother, Matthias, as the latter's troops attacked while Kepler and his family cowered in the city evoking parallels with battles today.

My wife and I have made several astronomy-related pilgrimages: to Prague to see the plaque over Kepler's lodgings and his joint statue with Tycho; to dine at the Golden Griffin where Tycho lodged for a time, now a restaurant and hotel; to visit a monument (we found it defaced) to Kepler in Regensburg, Bavaria, possibly near where his bones were originally buried until they were lost; and to see the house in Regensburg where Kepler died in 1630, now a museum. I was also able to help the Houghton Library at Harvard University in Cambridge, Massachusetts, acquire the only known copy of Kepler's 1603 almanac.

As Clark emphasizes, 1603 was thought to be particularly auspicious at the time. Rudolph II is quoted as saying, "Eight hundred years earlier, Charlemagne founded Europe; eight hundred years before him, Christ was born." Soon thereafter, Kepler saw a supernova - the last seen in our 
Galaxy and now named after him.

I could all but smell the streets and markets of seventeenth-century Prague in this novel. In one memorable passage, Clark describes Kepler taking the path to the castle, across the Stone Bridge, where in 1611 he wrote his little book on the snowflake, recently republished to celebrate its 400th anniversary.

Clark also brings to life interesting minor characters and conjures up Kepler's eventful family history, including the joys of parenthood, his difficult mother (whom he had to clear of suspicions of witchcraft), and the tragic deaths of his children and first wife, Barbara. Thoughtfully crafted dialogues reveal the tension between Kepler's rationalism and the 'magical' beliefs of others.

Interspersed among the chapters about Kepler are several about Galileo's

"The fun

of reading

plausible words

from the mouths

of Kepler

and Galileo

overwhelms

objections

to invented conversations."

time in Padua, Florence and Rome. In these, Kepler endorses the veracity of Galileo's reports of seeing new 'stars' around Jupiter through his newfangled optical tube. And Galileo's lack of response to a letter from Kepler is explained as a result of religious rivalry: the Catholic church in Rome feared that lapsed-Lutheran Kepler would side with their Protestant enemies.

Today, in an age when Vatican astronomers have telescopes in Arizona and host summer schools on cosmology at the Pope's summer residence at Castel Gandolfo near Rome, it is hard to evoke the mood of the early seventeenth century. Clark manages it.

Just as Shakespeare's inventions about the lives of kings give us too much pleasure to resist his playing fast and loose with history, the fun of reading plausible words from the mouths of Kepler, Galileo and their contemporaries overwhelms petty objections to invented conversations. I am less fond of Clark's minor chronological adjustments and his invented character, Cardinal Pippe.

The Sky's Dark Labyrinth deserves a broad readership. I look forward to Clark's forthcoming novel on Isaac Newton and Edmond Halley, and the final part of the trilogy, on Albert Einstein, Edwin Hubble and Georges Lemaître.

Jay M. Pasachoff is professor of astronomy at Williams College, Williamstown, Massachusetts, USA. e-mail:jay.m.pasachoff@williams.edu

\section{Q\&A Daphne Sheldrick Elephant rescuer}

Daphne Sheldrick was the first person to rear baby elephants successfully by hand, and has worked with animals for 50 years in Kenya. As she stars in an IMAX film chronicling her efforts, she describes her experience of conservation and animal husbandry.

\section{How did you get involved with elephants?}

I grew up on a highland

farm in Kenya. We had a lot of wild orphan animals because in those days wild animals were everywhere. I married into the wildlife service and lived in Tsavo National Park, where wild orphans started coming in - buffalo, rhinos and elephants. The elephants were a huge challenge: nobody had managed to raise a newborn calf. My husband thought it was impossible. Eventually I managed to keep one alive for six months, having lost many others. We knew we were on the right track.

\section{Why are elephants so challenging to rear?}

The milk formula is very special. So is the husbandry. It took 28 years of trial and error to get both about right. We knew that elephants' milk was high in fat. We added extra cream and butter to cows' milk, but then we learned that the elephants lived a lot longer on skimmed milk. So we scouted around the shops to try to find infant human formula that contained vegetable fat instead - the nearest thing to the fat in elephants' milk is coconut fat. With this mix, we have now managed to raise 130 elephants, which are still living today, some with their own young.

How do these animals become orphaned? Elephants are fragile in infancy. In a perfect world they would not have any enemies, but the growing human population is taking up more and more land that was once used for elephant migration routes. An elephant does not know the difference between grass and maize [corn] and can eat a human's livelihood in an afternoon. And the demand in the Far East for ivory has grown tremendously in the past few years. The only hope for elephants is to ban all trade in ivory.

\section{Have you shared your methods?}

We have tried to. We are contacted by people from all over Africa, but raising elephants is a long-term thing. They are with you for up to 10 years, sometimes longer. They need $\checkmark$ NATURE.COM

More on the surge in

the ivory trade:

go.nature.com/k9sgfk 24-hour care and feeding every 3 hours, day and night. They are milk-dependent for 3 years. You have got

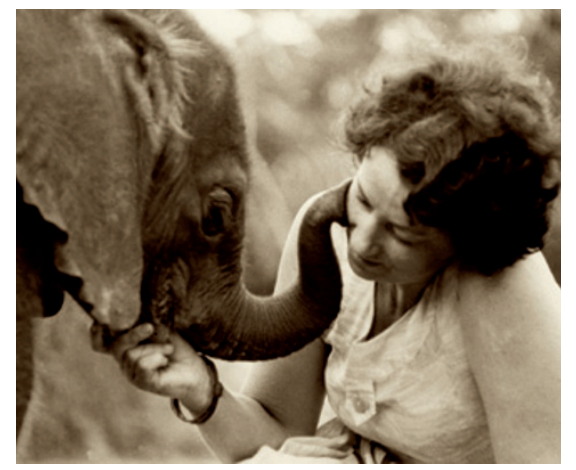

Daphne Sheldrick with one of her early charges.

to have the staying power to see the project through. I've been working with elephants for 50 years - that's most of my life.

\section{How do you return hand-raised elephants to the wild?}

They are one of the easiest species to return; it just takes a long time. It isn't a question of getting an animal to two or three years old and tipping it out in the bush. They go to the rehabilitation stations in Tsavo with their human family until they have made friends in the wild herds. They are introduced to the wild herds by other now-integrated orphans. No elephant we have raised has been unable to go wild in the fullness of time.

\section{What does the future hold for elephants in Africa?}

The elephant population in Africa will fall to a much lower level as the human population rises. But the absence of elephants has a big impact. They create the water holes and the trails that lead to them; they turn thick unproductive scrubland into productive grassland; they walk enormous distances and distribute seeds in their dung. Without the elephant you lose lots of other animals.

\section{What do you hope people will take away from Born to be Wild 3D?}

Everyone that sees it cannot fail to go home having learned a lot about elephants - how caring and nurturing they are and how magnificent they are to one another. Elephants can provide lots of lessons for humans. SEE CORRESPONDENCE P.282 